\title{
The impact of cleats on hydraulic fracture initiation and propagation in coal seams
}

\author{
Fan Tiegang ${ }^{1}$, Zhang Guangqing ${ }^{2 *}$ and Cui Jinbang ${ }^{3}$ \\ ${ }^{1}$ College of Mechanical and Transportation Engineering, China University of Petroleum, Beijing 102249, China \\ ${ }^{2}$ College of Petroleum Engineering, China University of Petroleum, Beijing 102249, China \\ ${ }^{3}$ CBM Branch Company, Huabei Oilfield Company, Changzhi, Shanxi 046000, China
}

(C) China University of Petroleum (Beijing) and Springer-Verlag Berlin Heidelberg 2014

\begin{abstract}
Cleats are systematic, natural fractures in coal seams. They account for most of the permeability and much of the porosity of coalbed methane reservoirs and can have a significant effect on the success of hydraulic fracturing stimulation. Laboratory hydraulic fracturing experiments were conducted on coal blocks under true tri-axial stress to simulate fracturing stimulation of coal seams. Fractures were initiated by injecting a water gel with luminous yellow fluorescent dye into an open hole section of a wellbore. The impact of cleats on initiation and propagation of hydraulic fractures in coal seams is discussed. Three types of hydraulic fracture initiation and propagation pattern were observed in this study: 1) The hydraulic fracture initiated and then grew along the cleat. 2) The hydraulic fracture initiated along a butt cleat or a fracture (natural or induced by drilling) oriented roughly in the minimum horizontal stress direction, then turned to propagate along the first face cleat that it encountered or gradually turned towards the maximum horizontal stress direction. 3) The hydraulic fracture initiated perpendicular to the minimum stress and, when it encountered a face cleat, tended to propagate along the cleats if the extension direction does not deviate greatly $\left(<20^{\circ}\right.$ as determined in this paper) from the maximum horizontal stress direction. When a coal seam is hydraulically fractured, the resulting fracture network is controlled by the combined effect of several factors: cleats determine the initiation and extension path of the fracture, the in-situ stress state dominates the main direction of the fracture zone and bedding planes impede fracture height growth.
\end{abstract}

Key words: Cleats, coalbed methane, hydraulic fracturing, coal seam, simulation experiment

\section{Introduction}

Coalbed methane (CBM) is a clean and high-quality unconventional gas resource associated with coal. Not only can the development and utilization of CBM compensate for shortages of conventional natural gas, but it can also effectively promote safe coal mine production and a reduction in emissions of greenhouse gases.

In the early 1980s, the United States successfully established a CBM industry (Moore, 2012). Subsequently, the success of CBM production has sparked intense interest worldwide, particularly among several coal-rich nations in Eastern Europe and Asia (Song et al, 2012).

Since the beginning of the CBM industry, operators have relied greatly on technology from the mining and petroleum industries to evaluate and develop CBM properties. Much of the conventional oil and gas technology translates to CBM operations, but often it must be modified. However, in some instances, CBM operations require entirely different

*Corresponding author. e-mail: zhangguangqing@cup.edu.cn Received April 23, 2014 techniques. Frequently, the unique characteristics of coal reservoirs are responsible for the need to develop a different engineering approach. While an unfractured well within a coal seam is difficult to justify economically, hydraulic fracturing may make a vertical well economically feasible (Deimbacher et al, 1992).

Unlike conventional gas reservoirs, the coal matrix permeability is extremely low. Gas in a CBM reservoir flows mainly through the natural fracture system of coal seams (Solano-Acosta et al, 2007; Moore, 2012). The purpose of hydraulic fracturing stimulation is to connect the wellbore with the natural fracture system reducing pressure losses caused by convergence of radial flow to the wellbore and to reduce the effect of near-well permeability damage. Hydraulic fracturing creates high conductivity channels in the reservoir that reduce the pressure required to introduce fluids to the well. Therefore, a key factor for CBM production is how to effectively connect a wellbore with the coal seam natural fracture system.

Hydraulic fractures usually initiate in the direction of maximum crustal stress, but in naturally fractured formations different alignments and trends of natural fractures, various 
crustal stresses and wellbore geometric configurations all contribute to differences in wellbore stress conditions, thus leading to various fracture initiation scenarios (Jeffrey et al, 2009; Zhang and Chen, 2009; 2010; Zhou et al, 2010; Chuprakov et al, 2011; Hou et al, 2013). The problem of hydraulic fracturing in coal seams has been widely investigated both experimentally (Khodaverdian et al, 1991; Penny et al, 1991; Fang and Khaksar, 2011) and numerically (Mavko et al, 1986; Ramurthy and Lyons, 2007; Wei et al, 2011). Many tests in the field (Diamond and Oyler, 1987; Palmer and Sparks, 1991; Jeffrey and Weber, 1994; Jeffrey et al, 1998) and in the laboratory (Abass et al, 1990; 1991) have shown that the geometry of hydraulic fractures that grow in the coal seam is very complex, and attributed that to the unique characteristics of coal seams, such as brittleness, high Poisson's ratio, low elastic modulus and the very development of the cleat system.

Diamond and Oyler (1987) reported observations of 22 mineback degasification wells that had been hydraulically stimulated. They observed that multiple and parallel fractures were common near the wellbore and that they became one single fracture as they propagated away from the wellbore. Most of the vertical fractures penetrated or paralleled face cleats and, occasionally, butt cleats of the coal seam. In several wells, fractures that paralleled face cleats did not intercept the wellbore when traced back. This was explained by a stair-step path that the hydraulic fractures had followed while alternating between the face and butt cleats. Jeffrey et al (1998) mapped three hydraulic fractures as the coal mine working passed through the site of the wells. They observed that the fractures at all three sites were affected by preexisting joint and cleat fractures in the coal. Some degree of multiple subparallel fracture development occurred in each case. The fracture at Appin was contained within the seam and the fracture at Munmorah grew into the floor rock but then became horizontal. Combined with observations of a downhole television camera, Palmer and Sparks (1991) showed that fractures in coal are complex. The fractures can be disjointed or multistranded. Additionally, shear slippage can occur at the coal/bounding-rock interface, and propping can be intermittent. Fractures in boundary zones adjacent to the coal seam are also complex. They can be thinner, disjointed, tortuous, and offset from the fracture in the coal. Abass et al $(1990 ; 1991)$ conducted hydraulic fracturing experiments on coal blocks in the laboratory. They noted that the mechanical properties of coal have a substantial influence on the hydraulic fracture geometry. Coal shrinkage resulting from coal degasification increases the chances for " $\mathrm{T}$ " shape or "I" shape fracture creation. Most of the hydraulic fracture is connected to the coal cleat, rather than a single plane fracture, although multiple fractures and fracturing fluid loss problems cannot be ignored.

Hydraulic fracture propagation in the presence of natural fractures is substantially different from those in reservoirs without natural fractures, as hydraulic fractures have complex growth patterns in formations with natural fracture systems resulting from significant diversion of hydraulic fracture paths when intersecting the natural fractures. The development of the hydraulic fractures is a process that includes the initiation of new fractures, propagation of fractures, opening or sliding of pre-existing fractures, and generation of additional fractures from critical points at an active site.

The objective of this paper is to better understand the effect of cleats on initiation and propagation of hydraulic fractures in coal reservoirs. To accomplish this, special attention is paid to the relative position between cleat and borehole, and the various orientations of the cleats. Dyed gelled water is injected into the specimen under a true triaxial stress state to show the created fracture geometry. This paper provides experimental results that would explain the unconventional field observations encountered during coal fracturing.

\section{The cleats in coal seams}

Fractures occur in nearly all coal seams. Coal fractures have been investigated since the early days of coal mining, and published descriptions and speculation on the origin of fractures date from early in the nineteenth century (Laubach et al, 1998). Although various miner's terms for systematic fractures in coal have been used over the years, they are still generally referred to by the ancient mining term: cleat (Dron, 1925).

Most gas and water flows through the coal cleat system and other fractures. Cleat is a miners' term for the natural system of vertical fractures that have formed in most coals, usually as a result of the coalification process. Typically, the cleat system in coal comprises two or more sets of subparallel fractures that are oriented nearly perpendicular to bedding. In contrast, fractures are characterized by irregular discontinuities that do not follow a defined pattern. Their seemingly random distribution distinguishes fractures from face and butt cleats.

Cleats normally have no shear offset. The set of fractures called the face cleat is usually dominant. The spacing of face cleat fractures may range from about a millimeter to hundreds of millimeters. The individual face cleats are relatively planar and persistent. Face cleat orientation is related to tectonic forces and is believed to form parallel to the maximum compressive stress. Typically, the butt cleat is perpendicular to the face cleat, but the fractures tend to be discontinuous and non-planar. Butt cleats commonly terminate against face cleats. Fig. 1 shows the pictures of cores cut from the coal seam under study.

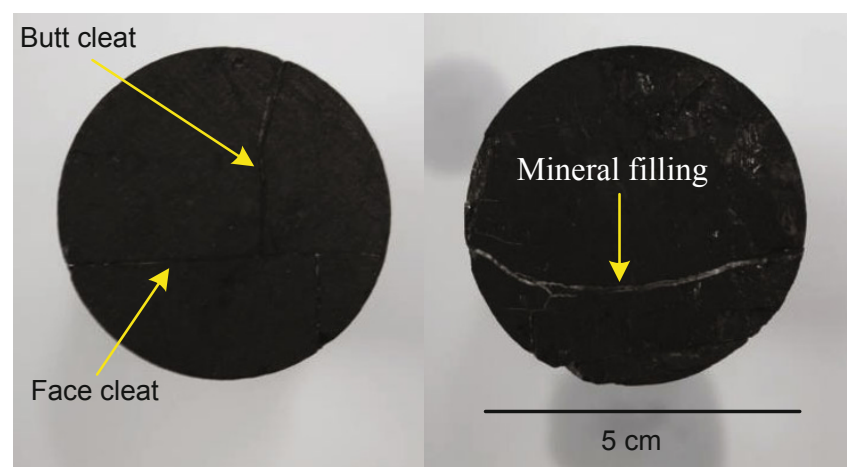

Fig. 1 Coal cores cut from the studied coal seam, showing cleats 


\section{Hydraulic fracturing experiment of coal}

\subsection{Experimental equipment}

The hydraulic fracturing experiments reported here were conducted using a true tri-axial hydraulic fracturing test system. All external stresses are supplied using a hydraulic voltage stabilizer, and the injection pressure is supplied using a servo-controlled hydraulic pump MTS 816. The system is capable of supplying external stresses of up to 28 $\mathrm{MPa}$ and injection pressures of up to $140 \mathrm{MPa}$ to a cubic specimen with an edge length of $30 \mathrm{~cm}$. The injection system is capable of pumping fluids with any injection scheme for continuous volumes up to $800 \mathrm{~mL}$. Experimental control and data acquisition are conducted using customized software running on a desktop computer. This system has been used successfully to initiate and propagate hydraulic fractures in a variety of materials using different fracturing fluids.

\subsection{Specimen preparation}

The coal specimens for the tests were collected from the Shenmu coal field, in the northeast of the Ordos Basin in Shaanxi, China. The blocks obtained in the field were irregular in shape and could not be used directly in the experiments. Therefore, the coal blocks were cut and finished with a saw-cutter into cubes of $30 \mathrm{~cm}$ on each side.

To study the effect of cleat orientation on the development of the hydraulic fractures, sampling was made in a variety of directions with respect to the face cleat of the coal blocks while keeping the bedding horizontal. Limited by the shape and dimension of original coal blocks, it was very difficult to control the sampling direction perfectly. The final orientations of the face cleat, as measured on the top surfaces of the specimens, are shown in Table 1. A processed standard specimen is shown in Fig. 2.

Table 1 Parameters used in the experiment

\begin{tabular}{cccccc}
\hline $\begin{array}{c}\text { Specimen } \\
\text { number }\end{array}$ & $\begin{array}{c}\beta^{*} \\
\text { degree }\end{array}$ & $\begin{array}{c}\text { Vertical stress } \\
\sigma_{\mathrm{v}}, \mathrm{MPa}\end{array}$ & $\begin{array}{c}\text { Maximum horizontal } \\
\text { stress } \sigma_{\mathrm{H}}, \mathrm{MPa}\end{array}$ & $\begin{array}{c}\text { Minimum horizontal } \\
\text { stress } \sigma_{\mathrm{h}}, \mathrm{MPa}\end{array}$ & $\begin{array}{c}\text { Injection rate of the fracturing } \\
\text { fluid } Q, \mathrm{~mL} / \mathrm{min}\end{array}$ \\
\hline 1 & 5 & 18 & 7 & 5 & 20 \\
2 & 7 & 18 & 7 & 5 & 20 \\
3 & 10 & 18 & 7 & 5 & 20 \\
4 & 11 & 18 & 7 & 5 & 20 \\
5 & 20 & 18 & 7 & 5 & 20 \\
6 & 39 & 18 & 7 & 5 & 20 \\
\hline
\end{tabular}

Notes: ${ }^{*} \beta$ is the angle between the face cleat and the maximum horizontal stress, degree.

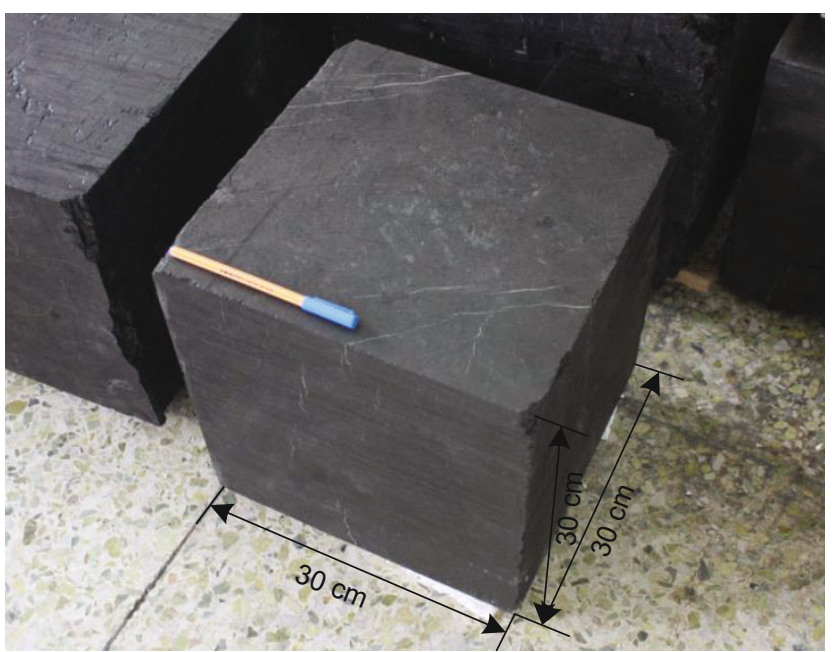

Fig. 2 The coal specimen for hydraulic fracturing test

The surfaces of specimens were ground flat, before a vertical borehole of $2 \mathrm{~cm}$ in diameter perpendicular to the bedding was drilled $16 \mathrm{~cm}$ deep. A metal casing with an inside diameter of $1 \mathrm{~cm}$ was inserted into the wellbores and cemented, leaving a $2 \mathrm{~cm}$ open borehole interval in the central part of the block for fracture initiation.

When testing, the specimens were placed into the true tri-axial pressure equipment. In our experiments, cubic specimens were loaded by three independent flatjacks to simulate in-situ stress conditions. Between the specimen and the flatjacks, we inserted a thin Teflon sheet covered on both sides with Vaseline to prevent shear stress (Pater and Beugelsdijk, 2005). We conducted our experiments in a normal-faulting stress regime. Confining stresses were raised hydrostatically to reach the minimum principal stress level, and then, the other two stresses were increased to the predetermined levels (see Table 1). Once the stresses reached their desired values, a delay of approximately 30 minutes allowed for the establishment of the stress equilibrium around the wellbore prior to the fracturing test (Kim and Abass, 1991).

For each experiment, the fracturing fluid with luminous yellow fluorescent dye was injected at a constant flow rate (see Table 1). The fracturing fluid was a guar-based gel with 5 grams of gel powder per liter of water. This gel has an apparent viscosity of approximately $24.7 \mathrm{cP}$. The fluorescent dye is non-penetrating and therefore highlights the fracture surface generated by the experiment. We kept pumping at a constant flow rate, monitoring as the pressure increased to a maximum value before suddenly decreasing. A sudden decrease in the pressure usually indicates fracture breakdown. We then estimated the fracture volume from the 
injection rate and pressure, to ensure that the fracture was fully developed and still fully contained within the sample, before ending the experiment by shutting down the pump. Finally, we depressurized the borehole and unloaded the triaxial equipment.

The post-test specimens were opened with a hammer and chisel along the expected fracture orientations. Under ultraviolet light, the luminous yellow fluorescent dye clearly showed the traces of hydraulic fractures.

\subsection{Experimental results}

After the experiments were performed, the specimens were cut to observe the geometry of the hydraulic fractures. The laboratory results indicated the features of hydraulic fractures in coal blocks are analogous to what is observed in other naturally fractured rocks, except that instead of initiating a new fracture, the development of hydraulic fracture system in coal blocks may start from opening cleats intersected by the wellbore.

\subsubsection{Initiation from cleats}

For Specimen 1, there was a vertical main hydraulic fracture along the maximum horizontal stress direction. When the specimen was split along the main hydraulic fracture, it was revealed that the fracture is primarily a straight vertical plane. However, due to the existence of a large number of cleats and convex or concave micro-fractures that formed during fracture propagation, the fracture surface is very rough (Fig. 3(a)).

Fig. 3(b) shows a cross section view of the specimen. The block was split along the horizontal plane that crosses the open borehole. It is noteworthy that the vertical plane of the main hydraulic fracture did not intersect the borehole, but propagated parallel to the vertical plane of the borehole separated by approximately $3 \mathrm{~cm}$. Hydraulic fractures were not initiated along the maximum horizontal stress direction, but along the minimum horizontal stress direction and extended symmetrically with the borehole as the center. The initial fracture A encountered a face cleat after it propagated approximately $3 \mathrm{~cm}$ on one side, then it propagated along the face cleat to form the main fracture. On the other side, the initial fracture B did not deflect significantly during propagation and did not encounter any large face cleats, so stopped propagating after the initial fracture A connected with the face cleat.

\subsubsection{Initiation from coal matrix}

For Specimen 2, there were no cleats and cracks around the borehole, thus the hydraulic fracture initiated within the coal matrix along the maximum horizontal stress direction.

As shown in Fig. 4, the specimen easily split along a vertical main hydraulic fracture with an approximately elliptic rough surface area around the borehole. The left wing of the fracture intersected with a face cleat after propagating approximately $6 \mathrm{~cm}$ in the coal matrix, and then it expanded along the flat cleat surface until it encountered the external surface of the specimen. On the right side, the main hydraulic fracture propagation distance was limited to approximately 9 $\mathrm{cm}$.

In the propagation process, the hydraulic fracture height
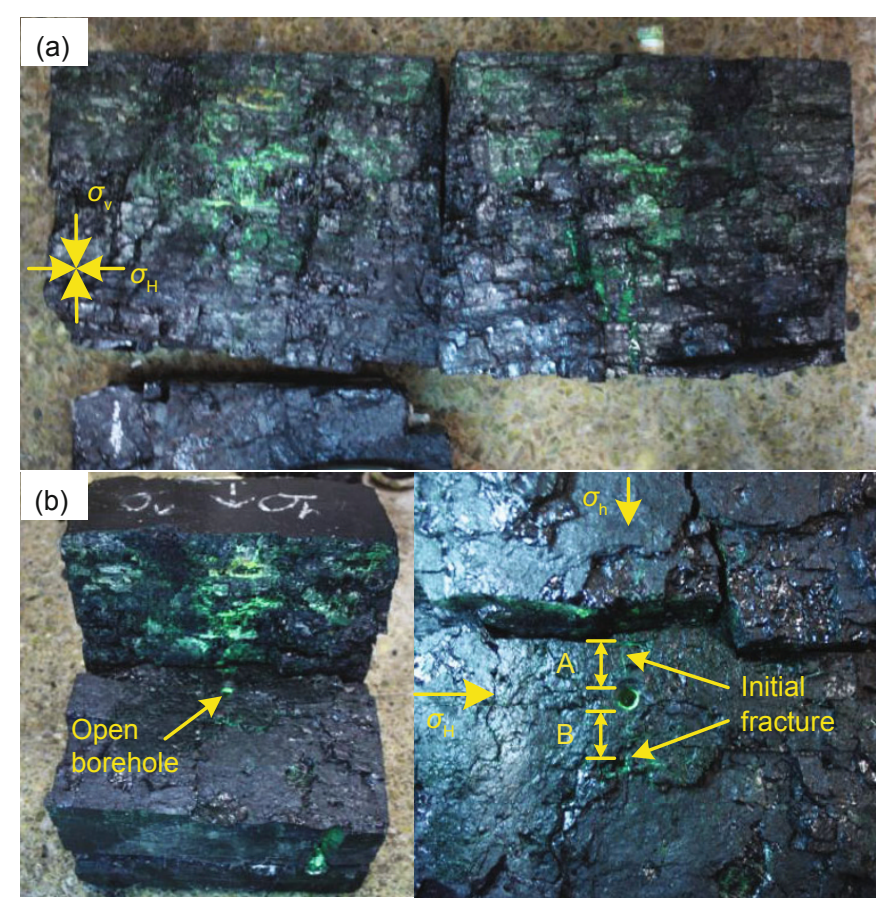

Fig. 3 The main fracture (a) and cross section (b) of Specimen 1

was controlled by bedding. The fractures were mainly distributed in the range of $6-20 \mathrm{~cm}$ away from the bottom of the specimen.

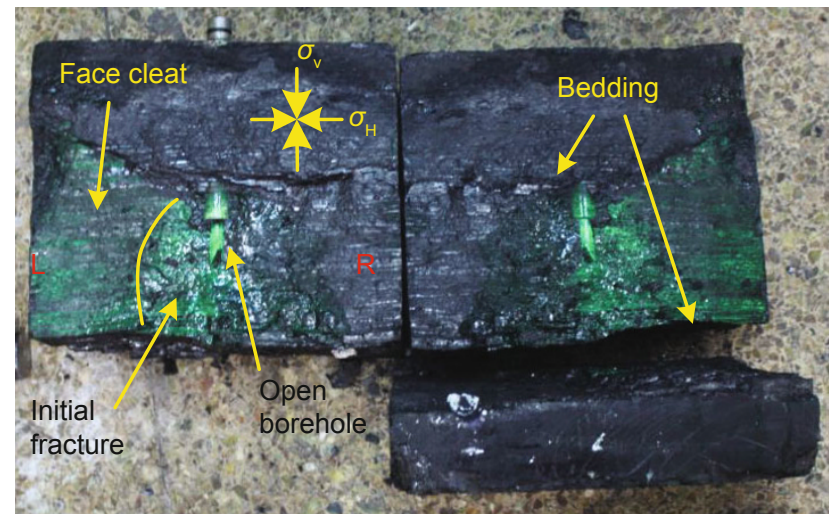

Fig. 4 The controlled fracture of Specimen 2

The fracture geometry characteristics of Specimen 5 are almost the same as Specimen 2, except that both wings of the fracture encountered the external surface and multiple fractures initiated at the borehole (see Fig. 5).

\subsubsection{Fracture reorientation}

For a normal faulting stress regime, when an oriented vertical fracture does not initiate perpendicular to the minimum horizontal stress, it will gradually turn towards the maximum horizontal stress direction during propagation controlled by the underground stress state. This phenomenon also occurs in these coal seam hydraulic fracturing experiments.

Fig. 6 shows the hydraulic fractures of Specimen 3 when opened along the horizontal cross section. An approximate $\mathrm{S}$ shape hydraulic fracture was observed that approached the minimum horizontal stress direction. 


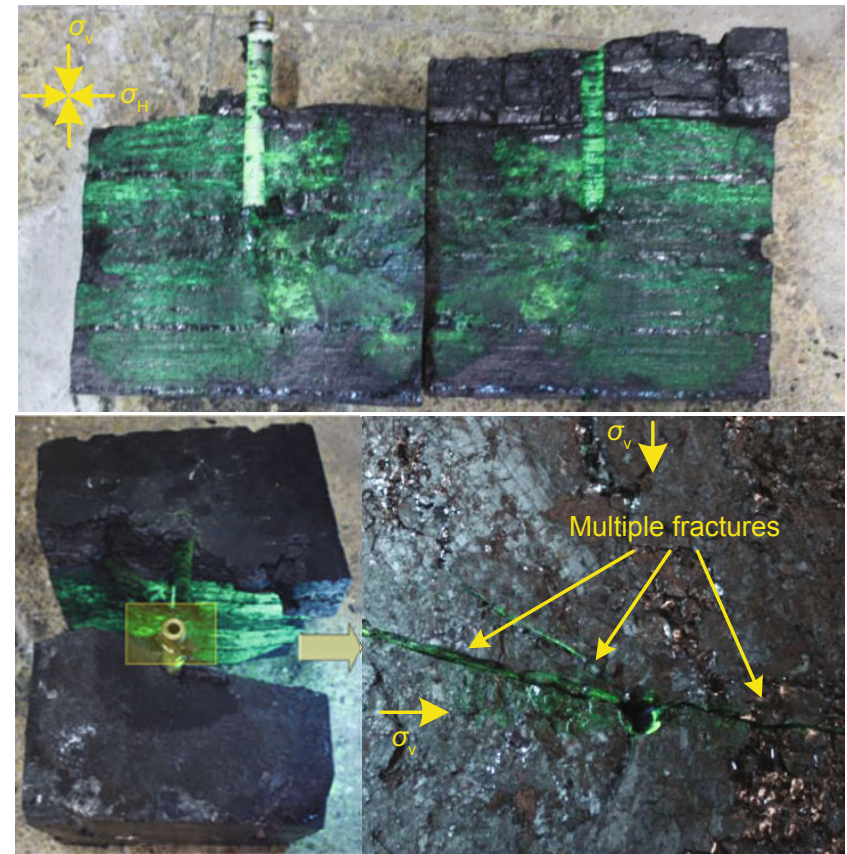

Fig. 5 Multiple fractures around the borehole of specimen 5

On the upper side, there were two initially sub-parallel fracture extensions, which then deflected to intersect with each other. The fractures continuously connected with cleats in the process of reorientation and the projection area of the fracture zone in the horizontal plane continuously widened. The hydraulic fracture turned to the maximum horizontal stress direction near the external surface of the specimen and the fracture network zone width increased to approximately $4.5 \mathrm{~cm}$.

On the underside, three hydraulic fractures initiated at the wall of wellbore. One of the fractures terminated after propagating $5 \mathrm{~cm}$, whereas the other fractures connected with a cleat and then propagated along the cleat in a straight line until reaching the specimen surface. The angle between the opened cleat and maximum horizontal stress direction is $59^{\circ}$.

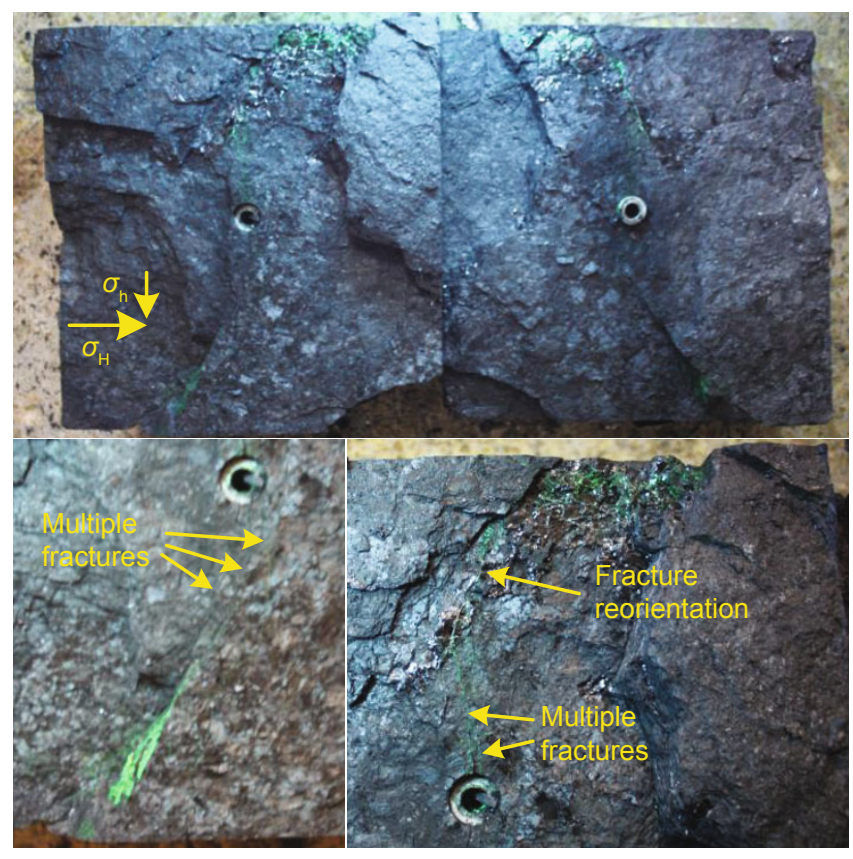

Fig. 6 View of cross section of Specimen 3

\section{The analysis of the influence of cleats on the development of hydraulic fractures}

Differing from the conventional single hydraulic fracture, the results of experiments on coal show complicated hydraulic fracture geometries. To reveal the initiation and propagation trajectories, the post-test block was cut into halves to examine the hydraulic fractures that developed. The distribution of the hydraulic fractures in the central horizontal plane for the tested specimens is shown in Fig. 7, which indicates that the fracture patterns were rather diverse. The pattern was not a single planar fracture, but a fracture network with most of the fractures formed by connecting cleats.

Direct observations of the experiments, as shown in Fig. 7, indicate that hydraulic fractures in coal do not always initiate

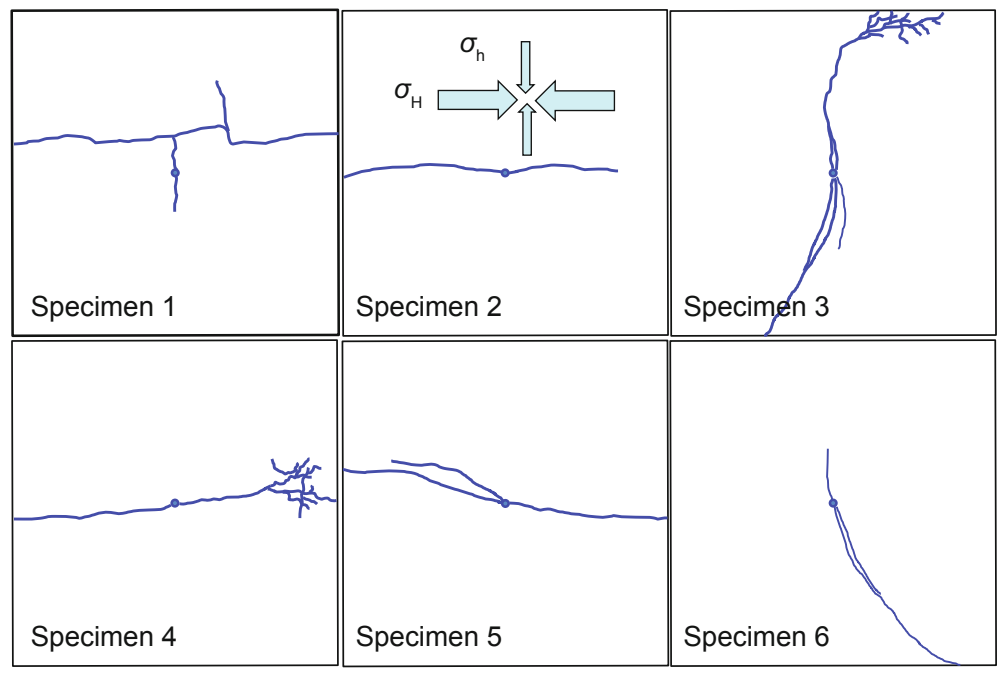

Fig. 7 The distribution of the hydraulic fractures in the central horizontal plane for the tested specimens 
along the direction of maximum horizontal stress. Instead, hydraulic fractures may grow from face or butt cleats, which is controlled by underground stress states, the mechanical behavior of coal and the borehole position relative to the cleats or fractures in coal. In summary, observations show three possible types of hydraulic fracture initiation and propagation:

Type 1 The hydraulic fracture initiated and then grew along a face cleat (see Fig. 8, Type 1). Specimen 4 is this type of system and had a long face cleat that, coincidentally, intersected with the borehole. As displayed in Table 1, the angle $\beta$ was $11^{\circ}$ and therefore the hydraulic fracture easily initiated by opening the cleat. In this case, only low fluid pressure in the borehole, which would be insufficient to initiate a new fracture, is necessary to open the cleat:

$$
p_{\mathrm{b} 1}<p_{\mathrm{bE}}=3 \sigma_{\mathrm{h}}-\sigma_{\mathrm{H}}+\sigma_{\mathrm{t}}-p
$$

where $p_{\mathrm{b} 1}$ is the tested breakdown pressure for case 1 type systems; $p_{\mathrm{bE}}$ is the breakdown pressure predicted by the elastic model (Hubbert and Willis, 1957); $\sigma_{\mathrm{h}}$ is the minimum horizontal stress; $\sigma_{\mathrm{H}}$ is the maximum horizontal stress; $\sigma_{\mathrm{t}}$ is the tensile strength of coal; $p$ is the pore pressure.

For Specimen 4, the breakdown pressure is $8.8 \mathrm{MPa}$.

Type 2 The hydraulic fracture initiated along a butt cleat or a fracture (natural or induced by drilling) oriented nearly parallel to the minimum horizontal stress direction, then turned to propagate along the first face cleat that it encountered or gradually turned to maximum horizontal stress direction (see Fig. 8, Type 2). Specimens 1, 3 and 6 are all examples of this type of system. In this type, the pressure of the fluid in the borehole is insufficient to initiate a new fracture, but should still be higher than the breakdown pressure of type 1:

$$
p_{\mathrm{b} 1}<p_{\mathrm{b} 2}<p_{\mathrm{bE}}=3 \sigma_{\mathrm{h}}-\sigma_{\mathrm{H}}+\sigma_{\mathrm{t}}-p
$$

where $p_{\mathrm{b} 2}$ is the tested breakdown pressure for case 2 type systems.

Note that a premise condition for type 2 is $3 \sigma_{\mathrm{h}}-\sigma_{\mathrm{H}}+\sigma_{\mathrm{t}}$ $>3 \sigma_{\mathrm{H}}-\sigma_{\mathrm{h}}$. If $3 \sigma_{\mathrm{h}}-\sigma_{\mathrm{H}}+\sigma_{\mathrm{t}}<3 \sigma_{\mathrm{H}}-\sigma_{\mathrm{h}}$, it will be easier for a new fracture to form in the direction of $\sigma_{\mathrm{H}}$ than a preexisting cleat adjacent to the borehole in the direction of $\sigma_{\mathrm{h}}$ to propagate.

The breakdown pressure of Specimens 1, 3 and 6 are 13.7, 19.1 and 15.5 MPa, respectively.

Type 3 The hydraulic fracture initiated perpendicular to the minimum stress, as predicted on the basis of traditional hydraulic fracturing theory (see Fig. 8, Type 3). Specimens 2 and 5 are case 3 type systems. When the initial hydraulic fracture encountered a face cleat, there was a tendency for the hydraulic fracture to propagate along the cleat if the propagation direction did not deviate substantially $\left(<20^{\circ}\right.$ as determined in this paper) from the maximum horizontal stress direction. As mentioned earlier, Hubbert and Willis (1957) derived the following breakdown pressure formula for impermeable materials:

$$
p_{\mathrm{bE}}=3 \sigma_{\mathrm{h}}-\sigma_{\mathrm{H}}+\sigma_{\mathrm{t}}-p
$$

For type 3 there should be:

$$
p_{\mathrm{b} 3}=p_{\mathrm{bE}}
$$

where $p_{\mathrm{b} 3}$ is the measured breakdown pressure for case 3 type systems.

According to the pressure records, the breakdown pressure of Specimens 2 and 5 are 24.2 and $32.8 \mathrm{MPa}$, respectively. Assuming the pore pressure is 0 , this model would give tensile strengths of 16.2 and $24.8 \mathrm{MPa}$ for the tested coal.

It is clear that these tensile strengths are much higher than any of the tested results $(0.2-3.7 \mathrm{MPa})$ that reported in literature (Shen and Zhang, 2000; Okubo et al, 2006; Zhu et al, 2009). One of the possible reasons for this abnormal outcome is that the reported tensile strengths are all obtained from the rock mechanical properties tests (such as Brazilian test or uniaxial tension test), which is performed on a given size of coal specimen. In these measurement methods, the cleats in coal cannot be disregarded, thus the presence of cleats is essential to the test. As described above for type 3, the tensile failure starts on the wall of a borehole that does not intersect any cleat or natural fracture, thus we reason that the fracture initiates on a smooth internal surface of the cylinder within the coal matrix. Furthermore, it has been recognized that coal shows significant scale effect, therefore the smallscale borehole (1 cm in diameter and $2 \mathrm{~cm}$ high) may also affect the tensile strength. Additional factors may contribute to the abnormal high breakdown pressures. However, there is currently insufficient research to address this question and it remains a topic for future investigation. Although the reason that our experiments derived such high tensile strengths is undetermined, it is evident that the breakdown pressure and derived tensile strength cannot be used directly at a field scale.

All of the above three types of hydraulic fracture initiation and propagation patterns indicate that the cleats near the borehole have a significant influence on the initiation of

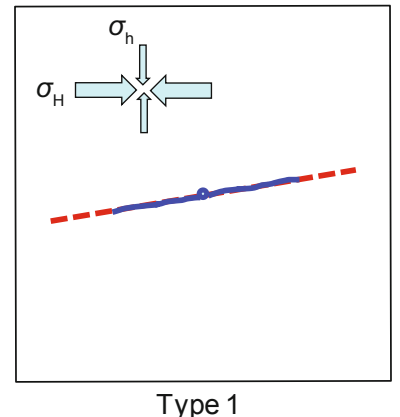

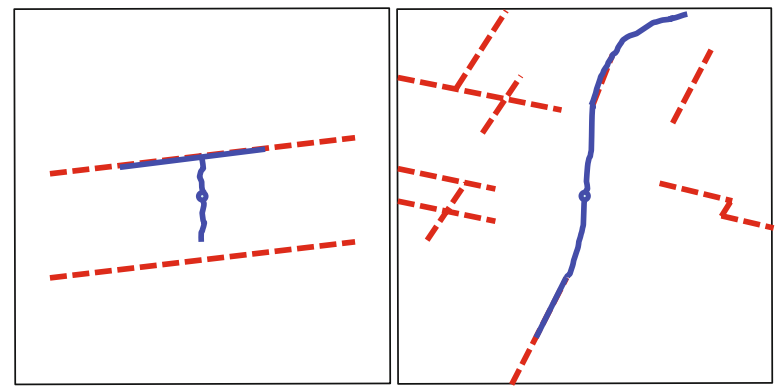

Type 2

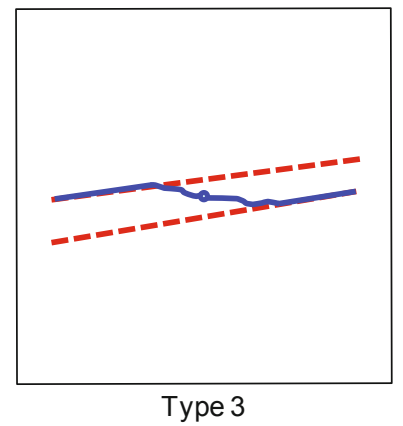

Type 3

Fig. 8 The observed three possible types of hydraulic fracture initiation and propagation patterns 
hydraulic fractures. When the fracturing fluid is continuously injected into the borehole and the fluid pressure rises above the minimum fracture pressure of coal, cleats open and one or multiple hydraulic fractures are formed near the borehole simultaneously. The initial fracture orientation is uncertain and determined by the distribution of the cleats on the borehole wall and the stress condition around the borehole. As the hydraulic fracturing continues, the number and form of these hydraulic fractures change. At the end of the experiment, there may be only one hydraulic fracture or there may be several hydraulic fractures.

In addition, in a coal seam that contains many cleats, we observed a tendency for the hydraulic fracture to propagate along the cleats. Opening a cleat whose plane is in line with the maximum horizontal stress direction requires the least pressure. When connecting to cleats with any other orientation, higher pressures are required to open or slide, which could lead to opening more cleats from different sites towards different directions. Eventually, multiple zigzag hydraulic fracture paths, instead of a single planar fracture, would be induced.

Another thing that must be noted is that, no matter how the fracture initiates or how complex the fracture network is, the system always has a dominant extension direction that is controlled by the in-situ stresses. When a fracturing process occurs in a coal seam, the hydraulic fracture will connect with the cleats and form a fracture network. The major axis of the fracture network most likely follows the direction of least resistance.

We attempted to control the orientation of cleats relative to the external force by directional sampling and by obtaining different specimens. However, the intersection of the borehole with cleats cannot be predicted and controlled, so we cannot present systematic results that show the properties that relate the cleat orientations to the initiation characteristics of the hydraulic fractures in this paper. But, from these results and analyses, we see that cleats do influence the propagation behavior of hydraulic fractures in coal formations, particularly in certain aspects, such as the breakdown pressure, initial fracture orientation and the geometry of hydraulic fractures. To improve the experiment results and obtain more general characteristics of these relationships, further studies and modifications are required.

\section{Conclusions}

Laboratory experiments were performed to investigate the impact of cleats on hydraulic fracture initiation and propagation in a coal seam. The following results were obtained in the present study:

1) Cleats significantly influence the hydraulic fracture initiation in a coal seam. When the open borehole intersects with cleats, the hydraulic fracture has a tendency to initiate by opening the cleat, rather than initiating a new fracture along the maximum horizontal stress direction.

2) The geometry of the hydraulic fracture network is affected not only by the in-situ stress regime but is also by the presence of multiple cleats. Hydraulic fracture networks are formed by the interactive process of reopening and connecting of the cleats, and multiple zigzag fracture paths are generated in the specimens.

3) Horizontal principal stress is the dominant control on the propagation direction of hydraulic fracture. Influenced by the existence of cleats on the borehole wall, the initiation direction of hydraulic fracture in a coal seam is uncertain. Regardless of the initial propagation direction, the direction of hydraulic fracture (zone/network) will eventually align with the maximum horizontal stress direction.

4) Hydraulic fracture height growth is constrained by bedding planes. Bedding is a weak plane in the coal seam and, when the growing hydraulic fracture intersects with a bedding plane in the vertical direction, the hydraulic fracture tip may slide along the bedding plane, confining the fracture between the coal bedding planes.

\section{Acknowledgements}

The authors gratefully acknowledge the support from the National Natural Science Foundation of China (Grant Nos. 51274216 and 51322404).

\section{References}

Abass H H, Hedayati S and Kim C M. Mathematical and experimental simulation of hydraulic fracturing in shallow coal seams. Paper SPE 23452 presented at SPE Eastern Regional Meeting, 22-25 October, 1991, Lexington, Kentucky

Abass H H, Van Domelen M L and El Rabaa W M. Experimental observations of hydraulic fracture propagation through coal blocks. Paper SPE 21289 presented at SPE Eastern Regional Meeting, 31 October-2 November, 1990, Columbus. Ohio

Chuprakov D A, Akulich A V, Siebrits E, et al. Hydraulic-fracture propagation in a naturally fractured reservoir. SPE Production \& Operations. 2011. 26(1): 88-97 (paper SPE 128715)

Deimbacher F X, Economides M J, Heinemann Z E, et al. Comparison of methane production from coalbeds using vertical or horizontal fractured wells. Journal of Petroleum Technology. 1992. 44(8): 930935 (paper SPE 21280)

Diamond W P and Oyler D C. Effects of stimulation treatments on coalbeds and surrounding strata - evidence from underground observations. U.S. Bureau of Mines. 1987 (RI 9083)

Dron R W. Notes on cleat in the Scottish coalfield. Transactions of the Institute of Mining Engineers. 1925. 70: 115-117

Fang $\mathrm{Z}$ and Khaksar A. Complexity of minifrac tests and implications for in-situ horizontal stresses in coalbed methane reservoirs. Paper IPTC-14630 presented at International Petroleum Technology Conference, 7-9 February, 2011, Bangkok, Thailand

Hou B, Chen M, Wang Z, et al. Hydraulic fracture initiation theory for a horizontal well in a coal seam. Petroleum Science. 2013. 10(2): 219225

Hubbert M K and Willis D G. Mechanics of hydraulic fracturing. Transactions of Society of Petroleum Engineers of AIME. 1957. 210: $153-168$

Jeffrey R G and Weber C R. Hydraulic fracturing experiments in the Great Northern Coal Seam. Paper SPE 28779 presented at SPE Asia Pacific Oil and Gas Conference, 7-10 November, 1994, Melbourne, Australia

Jeffrey R G, Vlahovic W, Doyle R P, et al. Propped fracture geometry of three hydraulic fractures in sydney basin coal seams. Paper SPE 50061 presented at SPE Asia Pacific Oil and Gas Conference and Exhibition, 12-14 October, 1998, Perth, Australia

Jeffrey R G, Zhang X and Thiercelin M J. Hydraulic fracture offsetting 
in naturally fractured reservoirs: quantifying a long-recognized process. Paper SPE 119351 presented at SPE Hydraulic Fracturing Technology Conference, 19-21 January, 2009, The Woodlands, Texas

Khodaverdian M, McLennan J D, Jones A H, et al. Examination of nearwellbore effects on hydraulic fracturing of coal. Paper ARMA-91201 presented at the 32nd U.S. Symposium on Rock Mechanics (USRMS), 10-12 July, 1991, Norman, Oklahoma

Kim C M and Abass H H. Hydraulic fracture initiation from horizontal wellbores: laboratory experiments. Paper ARMA-91-231 presented at the 32nd U.S. Symposium on Rock Mechanics (USRMS), 10-12 July, 1991, Norman, Oklahoma.

Laubach S E, Marrett R A, Olson J E, et al. Characteristics and origins of coal cleat: a review. International Journal of Coal Geology. 1998. 35(1-4): 175-207

Mavko B B, Hanson M E, Nielsen P E, et al. Hydraulic fracture model for application to coal seams. Paper ARMA-86-0741 presented at the 27th U.S. Symposium on Rock Mechanics (USRMS), 23-25 June, 1986, Tuscaloosa, AL

Moore T A. Coalbed methane: a review. International Journal of Coal Geology. 2012. 101: 36-81

Okubo S, Fukui K and Qi Q. Uniaxial compression and tension tests of anthracite and loading rate dependence of peak strength. International Journal of Coal Geology. 2006. 68(3-4): 196-204

Palmer I D and Sparks D P. Measurement of induced fractures by downhole TV camera in Black Warrior Basin Coalbeds. SPE Journal of Petroleum Technology. 1991. (3): 270-275+326-328 (paper SPE 20660)

Pater C J de and Beugelsdijk L J L. Experiments and numerical simulation of hydraulic fracturing in naturally fractured rock. Paper ARMA/USRMS 05-780 presented at Alaska Rocks 2005, the 40th U.S. Symposium on Rock Mechanics (USRMS), 25-29 June, 2005, Anchorage, AK

Penny G S, Conway M W and McBane R. Coordinated laboratory studies in support of hydraulic fracturing of coalbed methane. Paper
SPE 22911 presented at SPE Annual Technical Conference and Exhibition, 6-9 October, 1991, Dallas, Texas

Ramurthy M and Lyons W S. Lessons learned from modeling hydraulic fracture treatments in coals using a fully functional three dimensional fracture model in a San Juan Basin Project. Paper SPE 107972 presented at Rocky Mountain Oil \& Gas Technology Symposium, 16-18 April, 2007, Denver, Colorado, U.S.A.

Shen W and Zhang B. Testing study on mechanical parameters of coal. Chinese Journal of Rock Mechanics and Engineering. 2000. 19(S1): 860-862 (in Chinese)

Solano-Acosta W, Mastalerz M and Schimmelmann A. Cleats and their relation to geologic lineaments and coalbed methane potential in Pennsylvanian coals in Indiana. International Journal of Coal Geology. 2007. 72(3-4): 187-208

Song Y, Liu S, Zhang Q, et al. Coalbed methane genesis, occurrence and accumulation in China. Petroleum Science. 2012. 9(3): 269-280

Wei $\mathrm{H}, \mathrm{Li} \mathrm{L}, \mathrm{Wu} \mathrm{X}$, et al. The analysis and theory research on the factor of multiple fractures during hydraulic fracturing of CBM wells. Procedia Earth and Planetary Science. 2011. 3: 231-237

Zhang G Q and Chen M. Complex fracture shapes in hydraulic fracturing with orientated perforations. Petroleum Exploration and Development. 2009. 36(1): 103-107 (in Chinese)

Zhang G Q and Chen M. The relationship between the production rate and initiation location of new fractures in a refractured well. Petroleum Science and Technology. 2010. 28(7): 655-666

Zhou J, Jin Y and Chen M. Experimental investigation of hydraulic fracturing in random naturally fractured blocks. International Journal of Rock Mechanics and Mining Sciences. 2010. 47(7): 1193-1199

Zhu B C, Tang S H and Zhang J Z. Mechanics characteristics of coal and its roof and floor rock and the effects of hydraulic fracturing on coal reservoir. Journal of China Coal Society. 2009. 34(6): 756-760 (in Chinese)

(Edited by Sun Yanhua) 